\title{
Yttrium Y 90 Monoclonal Antibody B3
}

National Cancer Institute

\section{Source}

National Cancer Institute. Yttrium Y 90 Monoclonal Antibody B3. NCI Thesaurus. Code C2614.

A radioimmunoconjug ate of monoclonal antibody ( $M O A b) B 3$ conjug ated with isotope yttrium 90. MoAb B3 is a murine MoAb that recognizes a Lewis $Y$ carbohydrate antigen present on the surface of many carcinomas. This radioimmunoconjug ate emits beta particles that causes cytotoxicity in tumor cells and has both diagnostic and therapeutic uses. 